\title{
A Rearrangement of Allylic Silanols
}

\author{
Ranjeet Dhokale ${ }^{\mathrm{a}}$, Frederick J. Seidl ${ }^{\mathrm{b}}$, Shyam Sathyamoorthi ${ }^{\mathrm{a} *}$ \\ aDepartment of Medicinal Chemistry, University of Kansas, Lawrence, Kansas 66047, United States \\ bIndependent Researcher, San Bruno, CA 94066, United States
}

ABSTRACT: We show that $1 \mathrm{M} a q . \mathrm{HCl} / \mathrm{THF}$ or $\mathrm{NaBH}_{4} / \mathrm{DMF}$ allows for demercurative ring-opening of cyclic organomercurial
synthons into secondary silanol products bearing terminal alkenes. We had previously demonstrated that primary allylic silanols are
readily transformed into cyclic organomercurials using $\mathrm{Hg}(\mathrm{OTf})_{2} / \mathrm{NaHCO}_{3}$ in $\mathrm{THF}$. Overall, this amounts to a facile two-step proto-
col for the rearrangement of primary allylic silanol substrates. Computational investigations suggest that this rearrangement is under
thermodynamic control and that the di-tert-butylsilanol protecting group is essential for product selectivity.

\section{Introduction}

Rearrangement reactions can be grouped based on mechanism. One category contains true pericyclic reactions, involving a concerted flow of electrons which results in the breaking of a $\sigma$ bond, simultaneous rearrangement of a $\pi$ system, and formation of a new $\sigma$ bond. ${ }^{1}$ These rearrangements are effected thermally or through Lewis-Acid catalysis, and many landmark reactions (Cope, ${ }^{2}$ Claisen, ${ }^{3}$ Ireland-Claisen, ${ }^{4-7}$ Mislow-Evans, ${ }^{8}$ etc.) fall into this category. The second category contains formal sigmatropic processes, where the rearrangement proceeds through a discrete organometallic intermediate. A prominent example of this latter process is the Overman transposition of allylic trichloroacetimidates, which is catalyzed by either mercuric or palladium (II) salts (Scheme 1). ${ }^{9}$

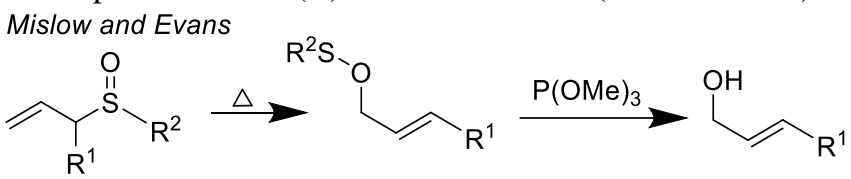

Overman<smiles>[R]C=CC([R])NC(=O)C(Cl)(Cl)C(=N)OC([R])C=C[R]</smiles>

This Work

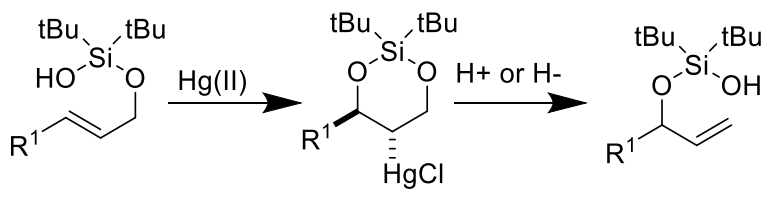

Scheme 1. Known allylic rearrangement reactions inspire this work.

In general, there are few rearrangement reactions of free and protected alcohols (Scheme 2). Pioneering work in this area was accomplished using early transition metal oxo species ${ }^{10-15}$ and with $\mathrm{Pd}$ (0)/Pd (II) salts. ${ }^{16-19}$ Elegant mechanistic studies of these reactions have been conducted by Henry, ${ }^{20}$ Osborn, ${ }^{21,} 22$ and Grubbs. ${ }^{23}, 24$ Recent advances have been provided by Floreancig, ${ }^{25-27}$ Zakarian, ${ }^{28}$ Lee, ${ }^{29-31}$ and others. ${ }^{32-34}$ Here, we describe a two-step protocol for a rearrangement of allylic silanols. We recently demonstrated a facile transformation of alkenyl silanols into organomecurial synthons. ${ }^{35}$ We now show that these organomercurial species can serve as intermediates for a transposition of the allylic silanol substrate.

Chabardes, Fujita, Takai

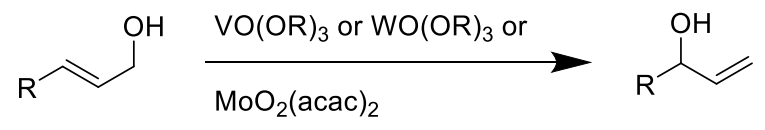

Osborn

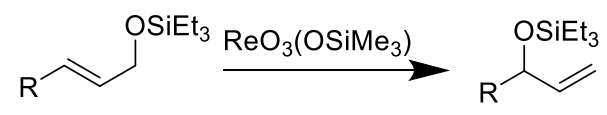

Tsuji and Trost

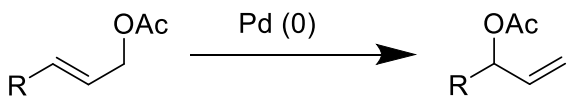

Overman

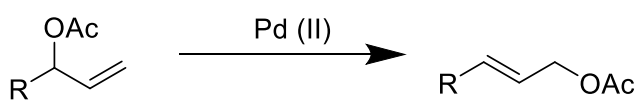

Scheme 2. Few protocols exist for the transposition of free and protected allylic alcohols.

\section{Results and Discussion}

\section{Synthetic Investigations}

This reaction was discovered serendipitously. To remove unreacted mercuric salts after the cyclization reaction, we explored using a $1 \mathrm{M}$ aqueous $\mathrm{HCl}$ workup. To our consternation, we recovered starting material with trace amounts of the rearranged product (Scheme 3). Repeating this experiment led to the same result. We thus realized that $1 \mathrm{M}$ aqueous $\mathrm{HCl}$ was promoting a de-mercuration reaction 
leading to starting material regeneration. We wondered if we could change the product distribution to favor the rearranged silanol.<smiles>C/C=C(/C)CO[Si](O)(C(C)(C)C)C(C)(C)C</smiles>

Scheme 3. $1 \mathrm{M}$ aqueous $\mathrm{HCl}$ promotes an allylic rearrangement reaction.

All attempts to improve the product distribution with A were unsuccessful. However, we observed a dramatic improvement upon switching to an organomercurial substrate with a pendant isopropyl group (Table 1, Entry 1). Increasing the reaction temperature gave identical results but dropping the temperature to $0{ }^{\circ} \mathrm{C}$ led to a decrease in yield and selectivity (Table 1, Entries 2-3). Interestingly, treatment with 2 equivalents of $\mathrm{NaBH}_{4}$ in either DMF or DMSO (Table 1, Entries 4-5) was equally effective in forming rearranged product. Demercuration reactions are known with $\mathrm{NaBH}_{4}$, but generally the products consist of mercury simply substituted with $\mathrm{H}, \mathrm{OH}$, or I. ${ }^{35}$ There was a profound solvent dependence on outcome with markedly worse reactions observed in $\mathrm{MeOH}, \mathrm{DMA}$, and THF (Table 1, Entries 6-8). Switching from $\mathrm{NaBH}_{4}$ to $\mathrm{LiBH}_{4}$ led to marked decomposition of substrate with little discernible product formation (Table 1, Entry 9).

Table 1. Optimization of this allylic rearrangement.

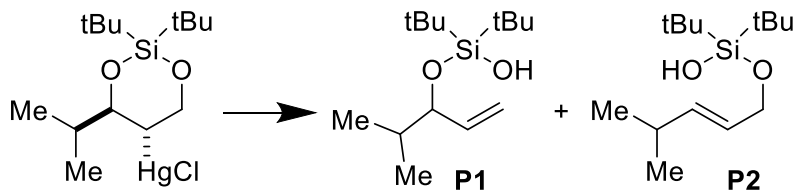

$\begin{array}{ccccr}\text { Entry } & \text { Reagent } & \text { Solvent } & \text { Temp.,Time } & {\mathrm{P} 1 / \mathrm{P}^{a}}^{a} \\ 1 & 1 \mathrm{M} \mathrm{HCl} \text { (aqueous) } & \text { THF } & \mathrm{RT}, 30 \mathrm{~min} & 60 / 20 \\ 2 & 1 \mathrm{M} \mathrm{HCl} \text { (aqueous) } & \mathrm{THF} & 35{ }^{\circ} \mathrm{C}, 30 \mathrm{~min} & 60 / 20 \\ 3 & 1 \mathrm{M} \mathrm{HCl} \text { (aqueous) } & \mathrm{THF} & 0{ }^{\circ} \mathrm{C}, 30 \mathrm{~min} & 50 / 22 \\ 4 & \mathrm{NaBH}_{4} \text { (2 equiv) } & \mathrm{DMF} & \mathrm{RT}, 30 \mathrm{~min} & 64 / 20 \\ 5 & \mathrm{NaBH}_{4} \text { (2 equiv) } & \mathrm{DMSO} & \mathrm{RT}, 30 \mathrm{~min} & 62 / 20 \\ 6 & \mathrm{NaBH}_{4} \text { (2 equiv) } & \mathrm{MeOH} & \mathrm{RT}, 30 \mathrm{~min} & 56 / 11 \\ 7 & \mathrm{NaBH}_{4} \text { (2 equiv) } & \mathrm{DMA} & \mathrm{RT}, 30 \mathrm{~min} & 6 / 4 \\ 8 & \mathrm{NaBH}_{4} \text { (2 equiv) } & \mathrm{THF} & \mathrm{RT}, 30 \mathrm{~min} & 43 / 7 \\ 9 & \mathrm{LiBH}_{4} \text { (2 equiv) } & \mathrm{THF} & \mathrm{RT}, 30 \mathrm{~min} & 10 / 0\end{array}$

${ }^{a}$ yield estimated using ${ }^{1} \mathrm{H}$ NMR integration against methyl phenyl sulfone as an internal standard

The nature of the substituent trans to the $\mathrm{HgCl}$ group greatly affected the ratio of the two regioisomeric products (Scheme 4). Generally, as the steric bulk of the linear alkyl chain increased, so too did the yield of the terminal alkene regioisomer (Scheme 4, Entries 1-3). With branching at the $\alpha$ carbon (Scheme 4, Entries 4-5) or at the $\beta$ carbon (Scheme 4, Entry 6), the terminal alkene regioisomer predominated. When there was competition between formation of a terminal alkene and its tri-substituted iso- mer, the more substituted olefin formed exclusively (Scheme 4, Entry 7).

Scheme 4. Alkene Substituents Markedly Affect Product Distribution<smiles>[R]C=CCO[Si](O)(C(C)(C)C)C(C)(C)C</smiles><smiles>C=CC(C)O[Si](O)(C(C)(C)C)C(C)(C)C</smiles>

3<smiles>C=CC(CCc1ccccc1)O[Si](O)(C(C)(C)C)C(C)(C)C</smiles>

4
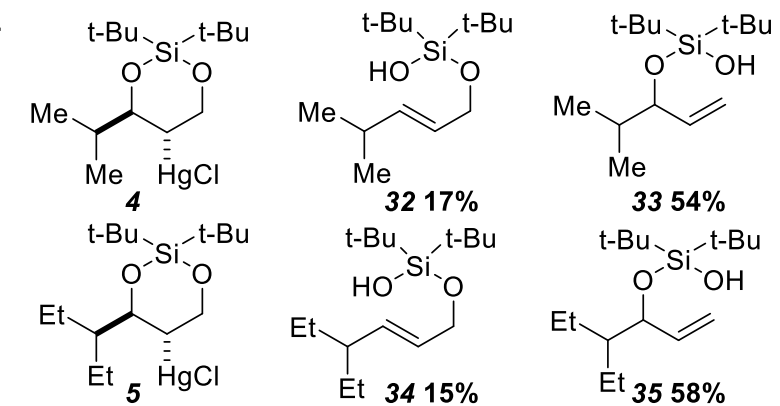

$3354 \%$<smiles>CCC(C=CCO[Si](O)(C(C)(C)C)C(C)(C)C)CCC(C)(C)C</smiles>

6<smiles>CC(C)C[C@H]1O[Si](C(C)(C)C)(C(C)(C)C)OC[C@H]1Cl</smiles><smiles>CC(C)C/C=C\CO[Si](O)(C(C)(C)C)C(C)(C)C</smiles><smiles>C=CC(O[Si](O)(C(C)(C)C)C(C)(C)C)C(CC)CCCCCC</smiles>

$3558 \%$ $\mathrm{t}-\mathrm{Bu} \mathbf{}_{-\mathrm{Si}}-\mathrm{t}-\mathrm{Bu}$<smiles>C=CC(CC(C)C)O[Si](C)(C)O</smiles>

7
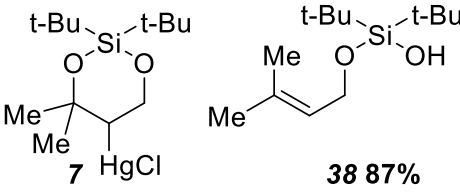

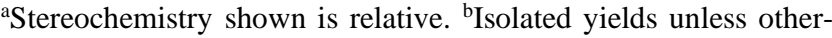
wise mentioned.

Our optimized protocols were compatible with a wide array of substrates (Scheme 5). While protocol A (1M aq. $\mathrm{HCl} / \mathrm{THF}$ ) was tested with the majority of substrates, protocol $\mathrm{B}\left(\mathrm{NaBH}_{4} / \mathrm{DMF}\right)$ was used for those bearing acid sensitive functionality (Scheme 5, Entries 1-2). In all but one instance (Scheme 5, Entry 10), terminal alkene products were greatly favored; in many cases (Scheme 5, Entries 1-3), these were the exclusive product. A variety of 
functional groups, including ketals (Scheme 5, Entries 12), halogens (Scheme 5, Entry 3; Scheme 5, Entry 6), and alkyl ethers (Scheme 5, Entry 3; Scheme 5, Entry 8) were well tolerated. We were pleased to successfully convert product $\mathbf{8}$ into a single diastereomer of a protected pentitol using a combination of catalytic $\mathrm{K}_{2} \mathrm{OsO}_{4} \cdot 2 \mathrm{H}_{2} \mathrm{O}$ and stoichiometric NMO (Scheme 6).

Scheme 5. Substrate Scope
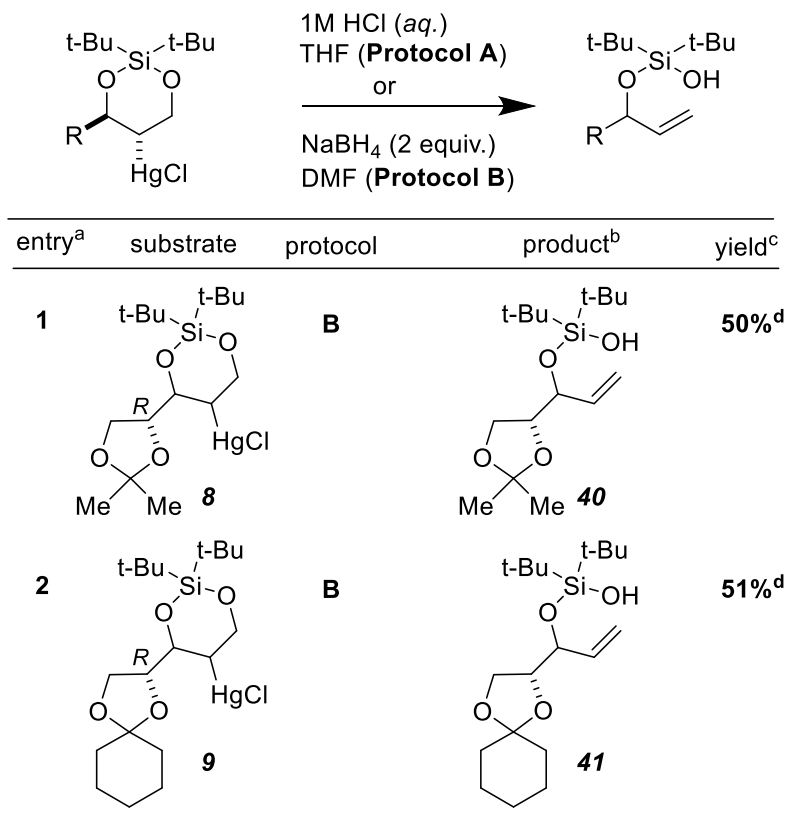<smiles>CC(C)C[Si]1(C(C)(C)C)OC[C@@H](Cl)C(C(C)Br)O1</smiles>
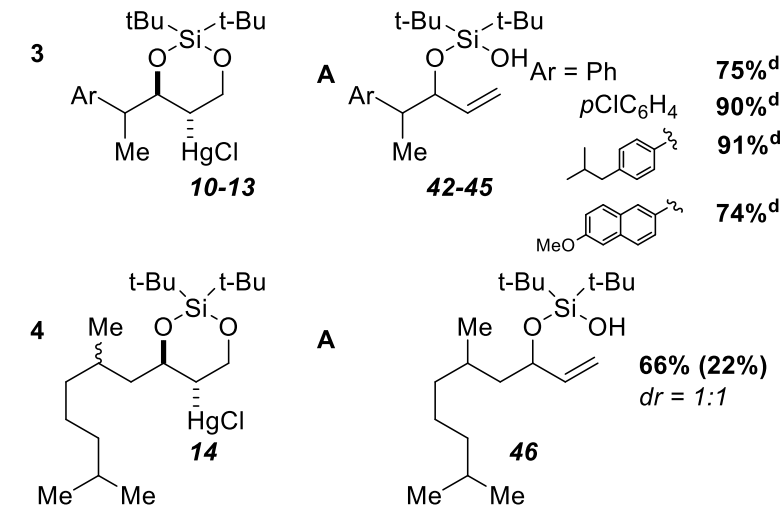

A

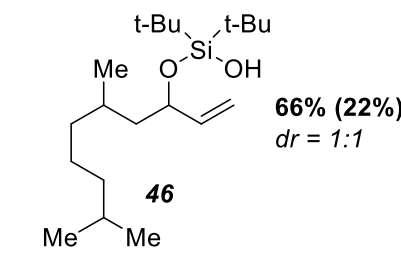

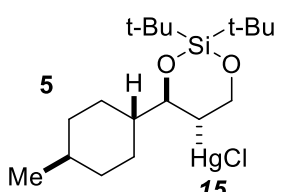

A<smiles>C=CC(O[Si](C)(C)C(C)(C)C)C1CCC(C)CC1</smiles>

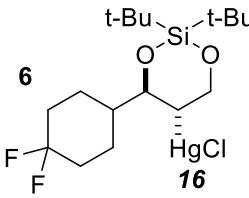

A<smiles>C=CC(O[13C](C)(C)C)C1CCC(F)(F)CC1</smiles>

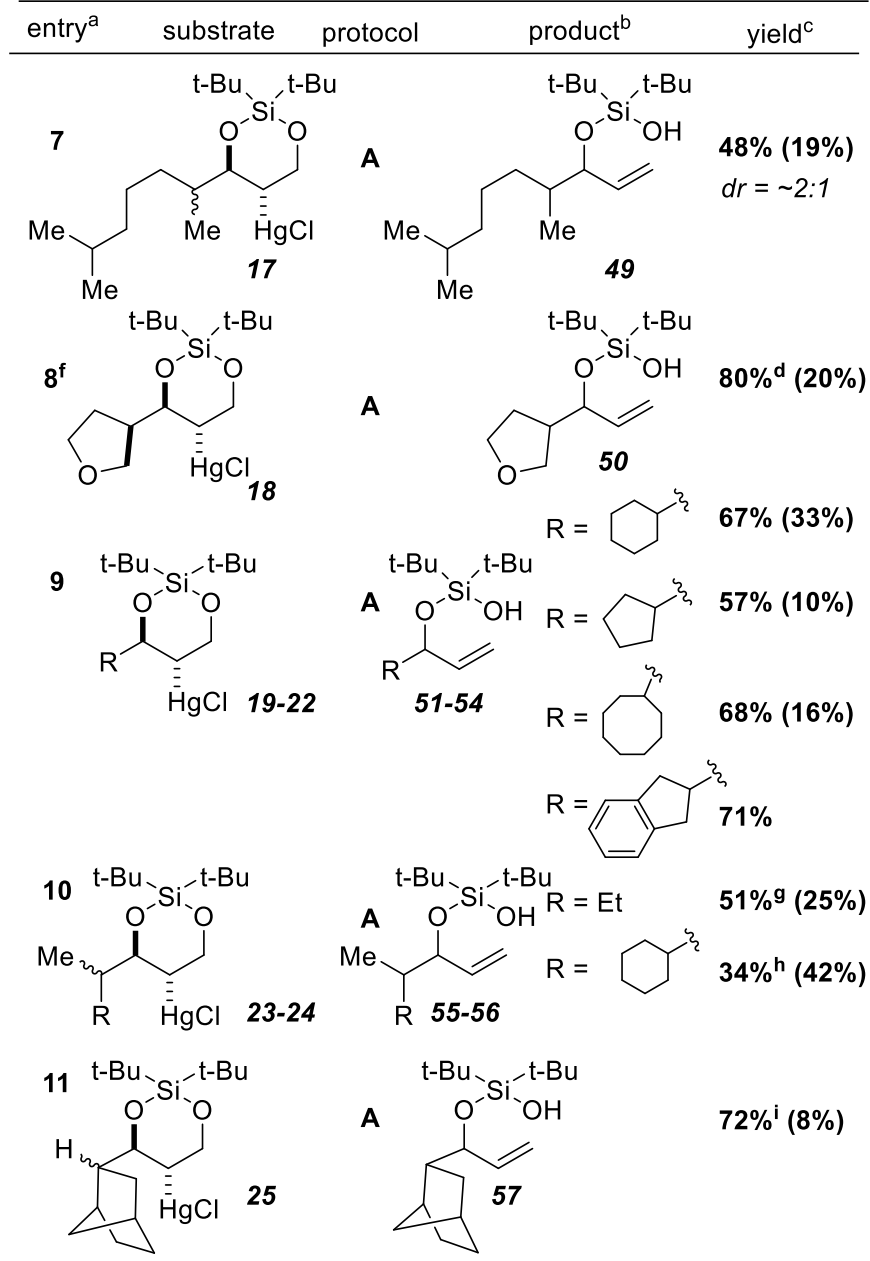

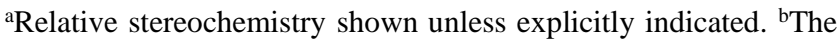
yield of the internal alkene regio-isomer is shown in parenthesis. ${ }^{c}$ Isolated yield unless otherwise mentioned. dSingle diastereomer but relative stereochemistry unassigned. ${ }^{e}$ Yield estimated using ${ }^{1} \mathrm{H}$ NMR integration against methyl phenyl sulfone as an internal standard. ${ }^{\mathrm{f}} \mathrm{CCDC}$ number 2052702. ${ }^{\mathrm{g}} \mathrm{dr}=\sim 1.5: 1 .{ }^{\mathrm{h}} \mathrm{dr}=\sim 2.5: 1$. ${ }^{\mathrm{i}}$ mixture of diastereomers

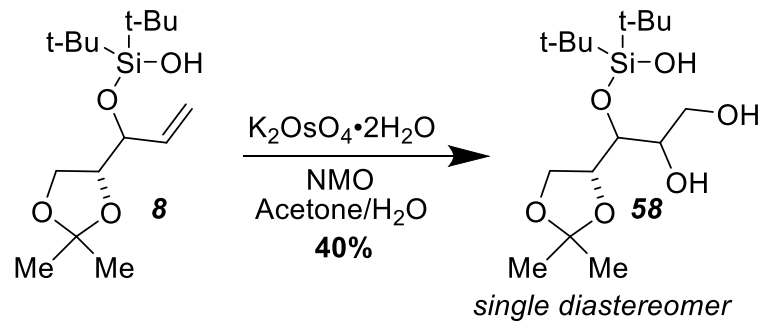

Scheme 6. Product 8 serves as a convenient precursor for a protected pentitol.

\section{Mechanistic Studies}

In order to better understand the observed selectivity we turned to DFT calculations using the ORCA software package. ${ }^{36,37}$ All calculations were performed using the B3LYP functional ${ }^{38,} 39$ with D3BJ dispersion correction $^{40,}{ }^{41}$ using the RIJCOSX approximation. ${ }^{42}$ The def2TZVP basis set $^{43}$ was used, and implicit water solvation 
was applied using the SMD model. ${ }^{44}$ When mercury was present, the def2-ECP ${ }^{45}$ was applied automatically. When multiple conformations were possible, a systematic rotor search was performed in Avogadro ${ }^{46}$ to identify the lowest energy conformation as a starting point. Further details and atomic coordinates are reported in the Supporting Information.

Noting that lower temperature led to lower selectivity for the terminal alkene isomer, we investigated the reaction thermodynamics to determine whether the product distribution was due to equilibrium or kinetics. The simplified reaction mechanism for protocol $\mathrm{A}$ is:

$$
\text { organomercury }+\mathrm{HCl} \rightarrow \text { alkene }+\mathrm{HgCl}_{2}
$$

For methyl substrate $\mathbf{1}$, the internal alkene $\mathbf{2 6}$ is calculated to be preferred by $0.9 \mathrm{kcal} / \mathrm{mol}$ (Figure 1). Experimentally, the observed 2.95:1 ratio favoring $\mathbf{2 6}$ over $\mathbf{2 7}$ corresponds to an expected $\Delta \mathrm{G}$ of $0.64 \mathrm{kcal} / \mathrm{mol}$ according to a Boltzmann population analysis at room temperature:

$$
\frac{A}{B}=\exp \frac{E(A)-E(B)}{k T}
$$

Figure 1. Calculated thermodynamics for methyl substrate 1

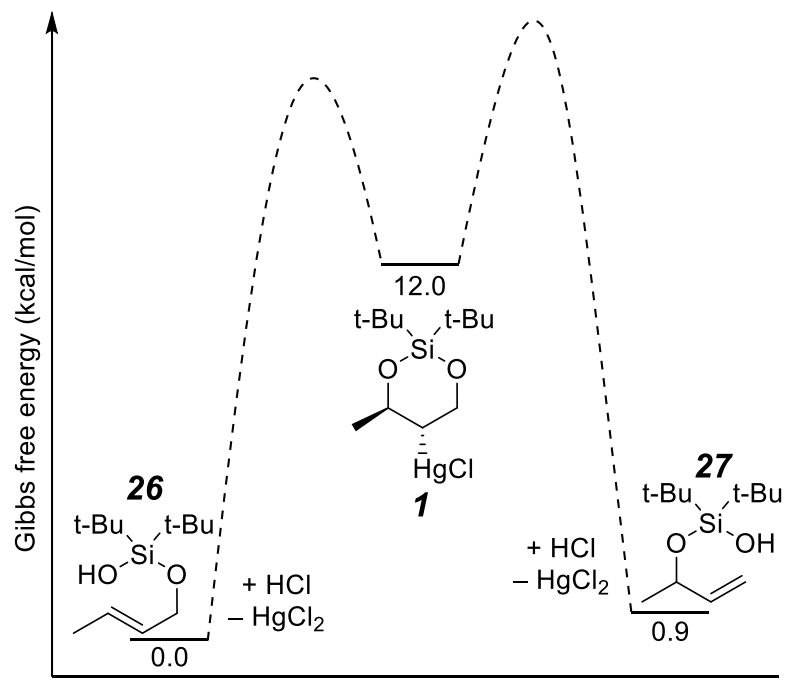

Reaction Coordinate

For isopropyl substrate $\mathbf{4}$, the terminal alkene $\mathbf{3 3}$ is calculated to be preferred by $0.5 \mathrm{kcal} / \mathrm{mol}$ (Figure 2). Experimentally, the observed 3.0:1 ratio favoring 33 over 32 corresponds to an expected $\Delta \mathrm{G}$ of $0.65 \mathrm{kcal} / \mathrm{mol}$ by the same equation above. Because these calculated values align reasonably well with experiment, it appears that the observed reaction selectivity is due to equilibrium thermodynamics.
Figure 2. Calculated thermodynamics for isopropyl substrate 4

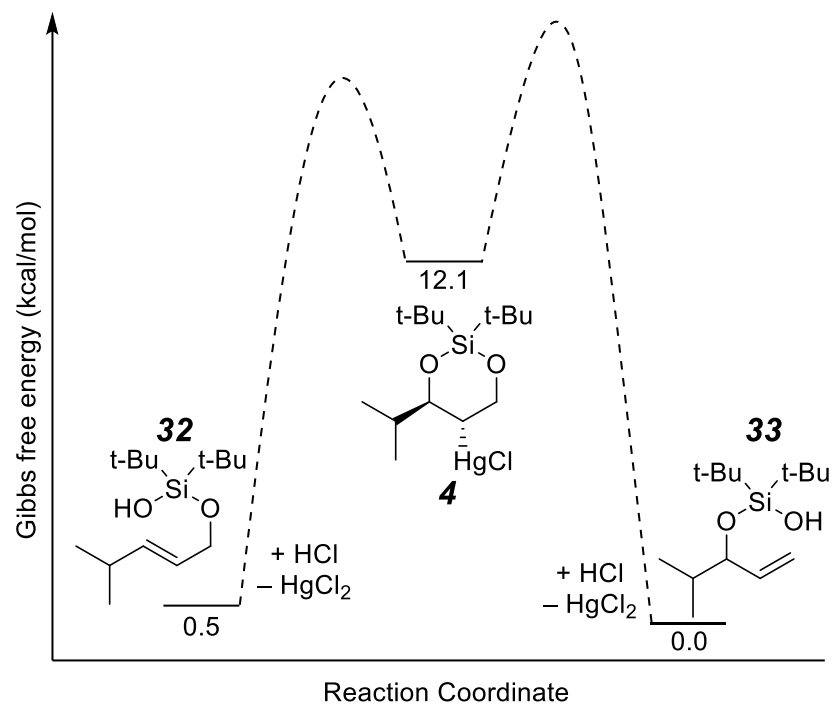

To better understand this thermodynamic preference, we also modeled the deprotected allylic alcohols. For methyl substrate $\mathbf{1}$, the internal alkene $(E)$-2-buten-1-ol was $0.02 \mathrm{kcal} / \mathrm{mol}$ higher in Gibbs Free Energy than terminal alkene 3-buten-2-ol or nearly isoenergetic. However, for isopropyl substrate 4, the internal alkene was $0.28 \mathrm{kcal} / \mathrm{mol}$ lower in Gibbs Free Energy than the terminal alkene. Importantly, the molecular dipole of the internal alkene is about 1 Debye larger than the dipole of the terminal alkene in both cases, so implicit water solvation significantly stabilizes the internal alkene with its larger molecular dipole. Because the deprotected allylic alcohols fail to account for the observed selectivity, we conclude that the pendant ditert-butylsilanol group plays a critical role in determining the thermodynamic selectivity of the reaction.

For the reaction to be under thermodynamic control, it must be reversible. The reaction barriers must be low enough to be overcome rapidly at room temperature (<20 kcal/mol). We began by modeling mercuronium rearrangements based on literature precedent for similar reactions. ${ }^{47}$ An intrinsic reaction coordinate (IRC) calculation from the rearrangement transition state leading to the major terminal alkene isomer $\mathbf{3 3}$ is included below (Figure 3). Starting from 4, the silanol oxygen is protonated to form 59, then the $\mathrm{C}-\mathrm{O}$ bond is broken with concomitant mercuronium formation. The transition state $\mathbf{6 0}$ is very late and product-like, and the potential energy surface in this region is very flat, complicating analysis. A stationary point could not be located for the discrete mercuronium product 61. Instead, 61 spontaneously engages in a 5-exo ring closure to reversibly re-form an isomeric alkylmercury species. This pathway is ultimately not productive as no sideproducts of this type are isolated experimentally. Most likely, mercuronium $\mathbf{6 1}$ is very short-lived and is rapidly abstracted by chloride to form $\mathrm{HgCl}_{2}$, which was not modeled. The overall calculated reaction pathway is exothermic by $12 \mathrm{kcal} / \mathrm{mol}$ and has an $8 \mathrm{kcal} / \mathrm{mol}$ barrier from SM 59 to TS 60. It follows that the reverse reaction starting from alkene 33 should have a barrier of about $20 \mathrm{kcal} / \mathrm{mol}$, 
which establishes the reaction as feasibly reversible at room temperature.

Figure 3. Mercuronium rearrangement of isopropyl substrate 4 (IRC calculation from the transition state)

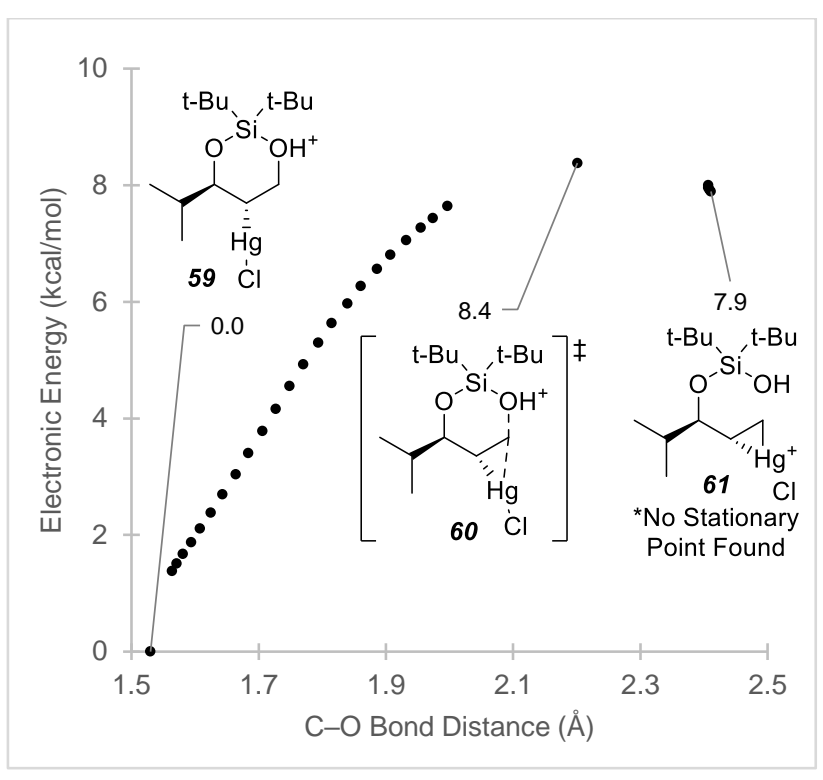

The same transition state analysis was performed for the pathway leading to the minor internal alkene product 32, for which a reaction barrier of only $5.1 \mathrm{kcal} / \mathrm{mol}$ was observed. Were this reaction under kinetic control, 32 would be overwhelmingly preferred over 33 with a $\Delta \Delta \mathrm{G}^{\ddagger}$ of over $3 \mathrm{kcal} / \mathrm{mol}$. This preference for a more substituted mercuronium ion is expected from Markovnikov selectivity rules due to the partial carbocation character of the mercuronium ion. Overall, for methyl organomercury substrate 1, the internal alkene $\mathbf{2 6}$ is favored by both thermodynamics and kinetics, whereas for isopropyl organomercury substrate 4, kinetics favors the internal alkene $\mathbf{3 2}$ and thermodynamics favors the terminal alkene $\mathbf{3 3}$

\section{Conclusion}

In summary, we present a two-step protocol for the rearrangement of allylic silanols. We had previously demonstrated that primary allylic silanols are readily transformed into cyclic organomercurials using $\mathrm{Hg}(\mathrm{OTf})_{2} / \mathrm{NaHCO}_{3}$ in THF. Here, we show that using either $1 \mathrm{M}$ aq. $\mathrm{HCl} / \mathrm{THF}$ or $\mathrm{NaBH}_{4} / \mathrm{DMF}$ allows for demercurative ring-opening to form secondary silanol products bearing terminal alkenes. Computational investigations suggest that this rearrangement is under thermodynamic control and that the di-tert-butylsilanol protecting group is essential for product selectivity.

\section{ASSOCIATED CONTENT}

Supporting Information. Experimental procedures, characterization of substrates and products, crystallographic data, and spectra. "This material is available free of charge via the Internet at http://pubs.acs.org."

\section{Corresponding Author}

*ssathyam@ku.edu

\section{ACKNOWLEDGMENT}

This work was supported by start-up funding provided jointly by the University of Kansas Office of the Provost and the Department of Medicinal Chemistry and an NIH COBRE Chemical Biology of Infectious Diseases Research Project Grant (P20GM113117). We thank Dr. Victor Day (University of Kansas) for X-ray crystallography analysis.

\section{REFERENCES}

1. Greer, E. M.; Cosgriff, C. V., Reaction mechanisms: pericyclic reactions. Annual Reports Section "B" (Organic Chemistry) 2013, 109, 328-350.

2. Graulich, N., The Cope rearrangement - the first born of a great family. WIREs Computational Molecular Science 2011, 1, 172-190.

3. Martín Castro, A. M., Claisen Rearrangement over the Past Nine Decades. Chemical Reviews 2004, 104, 2939. 3002.

4. Ito, H.; Taguchi, T., Asymmetric Claisen rearrangement. Chemical Society Reviews 1999, 28, 43-50.

5. Kesava Reddy, N.; Chandrasekhar, S., Total Synthesis of (-)- $\alpha$-Kainic acid via Chirality Transfer through Ireland-Claisen Rearrangement. The Journal of Organic Chemistry 2013, 78, 3355-3360.

6. Qin, Y.-c.; Stivala, C. E.; Zakarian, A., Acyclic Stereocontrol in the Ireland-Claisen Rearrangement of $\alpha$ Branched Esters. Angewandte Chemie International Edition 2007, 46, 7466-7469.

7. Fulton, T. J.; Cusumano, A. Q.; Alexy, E. J.; Du, Y. E.; Zhang, H.; Houk, K. N.; Stoltz, B. M., Global Diastereoconvergence in the Ireland-Claisen Rearrangement of Isomeric Enolates: Synthesis of Tetrasubstituted $\alpha$-Amino Acids. Journal of the American Chemical Society 2020, 142, 21938-21947.

8. Li, J. J., Mislow-Evans rearrangement. In Name Reactions: A Collection of Detailed Mechanisms and Synthetic Applications, Li, J. J., Ed. Springer Berlin Heidelberg: Berlin, Heidelberg, 2009; pp 363-364.

9. Overman, L. E., Molecular rearrangements in the construction of complex molecules. Tetrahedron 2009, 65, 6432-6446.

10. Chabardes, P.; Kuntz, E.; Varagnat, J., Use of oxo-metallic derivatives in isomerisation: Reactions of unsaturated alcohols. Tetrahedron 1977, 33, 1775-1783.

11. Volchkov, I.; Lee, D., Recent developments of direct rhenium-catalyzed [1,3]-transpositions of allylic alcohols and their silyl ethers. Chemical Society Reviews 2014, 43, 4381-4394.

12. Matsubara, S.; Takai, K.; Nozaki, H., Isomerization of primary allylic alcohols to tertiary ones by means of Me3SiOOSiMe3-VO(acac)2 catalyst. Tetrahedron Letters 1983, 24, 3741-3744.

13. Hosogai, T.; Fujita, Y.; Ninagawa, Y.; Nishida, T., Selective Allylic Rearrangement With Tungsten Catalyst. Chemistry Letters 1982, 11, 357-360.

\section{AUTHOR INFORMATION}


14. Belgacem, J.; Kress, J.; Osborn, J. A., On the allylic rearrangements in metal oxo complexes: mechanistic and catalytic studies on MoO2(allyloxo)2(CH3CN)2 and analogous complexes. Journal of the American Chemical Society 1992, 114, 1501-1502.

15. Narasaka, K.; Kusama, H.; Hayashi, Y., Rearrangement of Allylic and Propargylic Alcohols Catalyzed by the Combined Use of tetrabutylammonium perrhenate (VII) and p-toluenesulfonic acid. Tetrahedron 1992, 48, 2059-2068.

16. Tsuji, J., Dawn of organopalladium chemistry in the early 1960s and a retrospective overview of the research on palladium-catalyzed reactions. Tetrahedron 2015, 71, 6330-6348.

17. Trost, B. M.; Van Vranken, D. L., Asymmetric Transition Metal-Catalyzed Allylic Alkylations. Chemical Reviews 1996, 96, 395-422.

18. Overman, L. E., Mercury(II)- and Palladium(II)Catalyzed [3,3]-Sigmatropic Rearrangements [New Synthetic Methods (46)]. Angewandte Chemie International Edition in English 1984, 23, 579-586.

19. Overman, L. E.; Knoll, F. M., Palladium (II) catalyzed rearrangement of allylic acetates. Tetrahedron Letters 1979, 20, 321-324.

20. Henry, P. M., Palladium(II)-catalyzed exchange and isomerization reactions. III. Allylic esters isomerization in acetic acid catalyzed by palladium(II) chloride. Journal of the American Chemical Society 1972, 94, 5200-5206.

21. Belgacem, J.; Kress, J.; Osborn, J. A., Catalytic oxidation and ammoxidation of propylene. Modelling studies on well-defined molybdenum complexes. Journal of Molecular Catalysis 1994, 86, 267-285.

22. Bellemin-Laponnaz, S.; Gisie, H.; Le Ny, J. P.; Osborn, J. A., Mechanistic Insights into the Very Efficient [ReO3OSiR3]-Catalyzed Isomerization of Allyl Alcohols. Angewandte Chemie International Edition in English 1997, 36, 976-978.

23. Morrill, C.; Beutner, G. L.; Grubbs, R. H., Rhenium-Catalyzed 1,3-Isomerization of Allylic Alcohols: Scope and Chirality Transfer. The Journal of Organic Chemistry 2006, 71, 7813-7825.

24. Morrill, C.; Grubbs, R. H., Highly Selective 1,3Isomerization of Allylic Alcohols via Rhenium Oxo Catalysis. Journal of the American Chemical Society 2005, 127, 2842-2843.

25. Xie, Y.; Floreancig, P. E., Stereoselective heterocycle synthesis through a reversible allylic alcohol transposition and nucleophilic addition sequence. Chemical Science 2011, 2, 2423-2427.

26. Jung, H. H.; Seiders Ii, J. R.; Floreancig, P. E., Oxidative Cleavage in the Construction of Complex Molecules: Synthesis of the Leucascandrolide A Macrolactone. Angewandte Chemie International Edition 2007, 46, 8464-8467.

27. Xie, Y.; Floreancig, P. E., Cascade Approach to Stereoselective Polycyclic Ether Formation: Epoxides as Trapping Agents in the Transposition of Allylic Alcohols.
Angewandte Chemie International Edition 2013, 52, 625628.

28. Herrmann, A. T.; Saito, T.; Stivala, C. E.; Tom, J.; Zakarian, A., Regio- and Stereocontrol in RheniumCatalyzed Transposition of Allylic Alcohols. Journal of the American Chemical Society 2010, 132, 5962-5963.

29. Lee, D.; Volchkov, I., Chapter 7 - Regio- and Stereoselective Metal-Catalyzed Reactions and Their Application to a Total Synthesis of (-)-Dactylolide. In Strategies and Tactics in Organic Synthesis, Harmata, M., Ed. Academic Press2012; Vol. 8, pp 171-197.

30. Volchkov, I.; Park, S.; Lee, D., Ring StrainPromoted Allylic Transposition of Cyclic Silyl Ethers. Organic Letters 2011, 13, 3530-3533.

31. Volchkov, I.; Lee, D., Asymmetric Total Synthesis of (-)-Amphidinolide $\mathrm{V}$ through Effective Combinations of Catalytic Transformations. Journal of the American Chemical Society 2013, 135, 5324-5327.

32. Zheng, H.; Lejkowski, M.; Hall, D. G., Mild and selective boronic acid catalyzed 1,3-transposition of allylic alcohols and Meyer-Schuster rearrangement of propargylic alcohols. Chemical Science 2011, 2, 1305-1310.

33. Mandal, A. K.; Schneekloth, J. S.; Kuramochi, K.; Crews, C. M., Synthetic Studies on Amphidinolide B1. Organic Letters 2006, 8, 427-430.

34. Trost, B. M.; Toste, F. D., Enantioselective Total Synthesis of (-)-Galanthamine. Journal of the American Chemical Society 2000, 122, 11262-11263.

35. Shinde, A. H.; Sathyamoorthi, S., Tethered Silanoxymercuration of Allylic Alcohols. Organic Letters 2020, 22, 8665-8669.

36. Neese, F., The ORCA program system. WIREs Computational Molecular Science 2012, 2, 73-78.

37. Neese, F., Software update: the ORCA program system, version 4.0. WIREs Computational Molecular Science 2018, 8, e1327.

38. Becke, A. D., A new mixing of Hartree-Fock and local density-functional theories. The Journal of Chemical Physics 1993, 98, 1372-1377.

39. Lee, C.; Yang, W.; Parr, R. G., Development of the Colle-Salvetti correlation-energy formula into a functional of the electron density. Physical Review B 1988, 37, 785-789.

40. Grimme, S.; Antony, J.; Ehrlich, S.; Krieg, H., A consistent and accurate ab initio parametrization of density functional dispersion correction (DFT-D) for the 94 elements $\mathrm{H}-\mathrm{Pu}$. The Journal of Chemical Physics 2010, $132,154104$.

41. Grimme, S.; Ehrlich, S.; Goerigk, L., Effect of the damping function in dispersion corrected density functional theory. Journal of Computational Chemistry 2011, 32, 1456-1465.

42. Weigend, F., Accurate Coulomb-fitting basis sets for H to Rn. Physical Chemistry Chemical Physics 2006, 8, 1057-1065.

43. Weigend, F.; Ahlrichs, R., Balanced basis sets of split valence, triple zeta valence and quadruple zeta valence quality for $\mathrm{H}$ to $\mathrm{Rn}$ : Design and assessment of accuracy. Physical Chemistry Chemical Physics 2005, 7, 3297-3305. 
44. Marenich, A. V.; Cramer, C. J.; Truhlar, D. G., Universal Solvation Model Based on Solute Electron Density and on a Continuum Model of the Solvent Defined by the Bulk Dielectric Constant and Atomic Surface Tensions. The Journal of Physical Chemistry B 2009, 113, 6378-6396.

45. Andrae, D.; Häußermann, U.; Dolg, M.; Stoll, H.; Preuß, H., Energy-adjustedab initio pseudopotentials for the second and third row transition elements. Theoretica chimica acta 1990, 77, 123-141.

46. Hanwell, M. D.; Curtis, D. E.; Lonie, D. C.; Vandermeersch, T.; Zurek, E.; Hutchison, G. R., Avogadro: an advanced semantic chemical editor, visualization, and analysis platform. Journal of Cheminformatics 2012, 4, 17. 47. Bordwell, F. G.; Douglass, M. L., Reduction of Alkylmercuric Hydroxides by Sodium Borohydride. Journal of the American Chemical Society 1966, 88, 993999. 
Insert Table of Contents artwork here

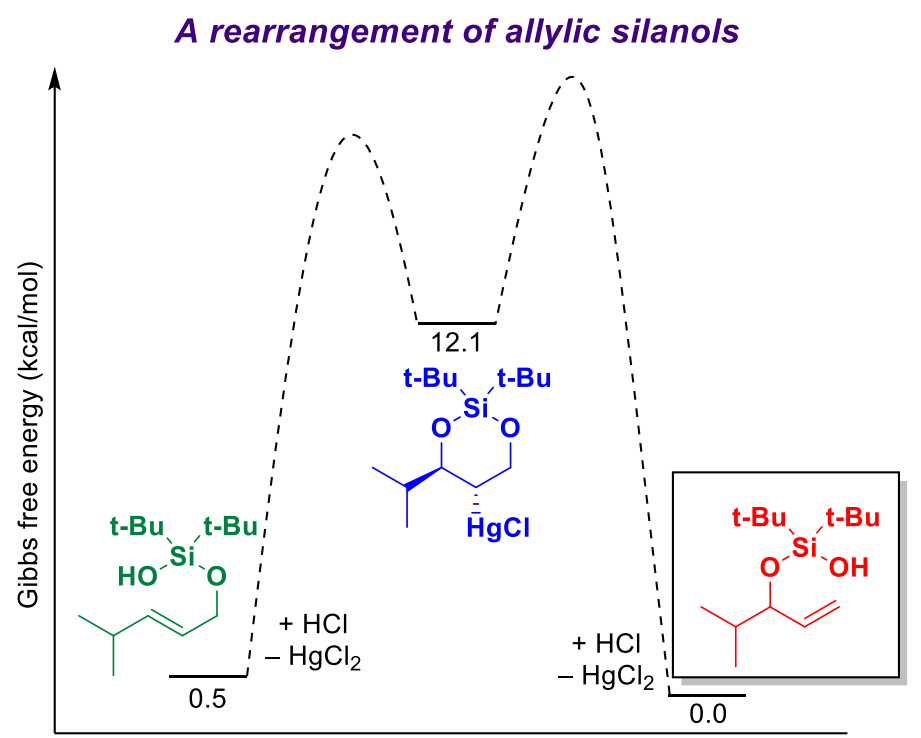

Reaction Coordinate 